\title{
Lasteaiaõpetajate ja koolieelse lasteasutuse õpetajaks õppivate üliõpilaste hinnangud oma aine-, pedagoogika- ja tehnoloogiateadmistele ning nende teadmiste integreerimisele
}

\author{
Piret Luik ${ }^{\mathrm{a}}$, Merle Taimalu ${ }^{\mathrm{b}}$ \\ ${ }^{a}$ Tartu Ülikooli arvutiteaduse instituut \\ ${ }^{b}$ Tartu Ülikooli haridusteaduste instituut
}

\begin{abstract}
Annotatsioon
Digitehnoloogia on kujunenud hariduse osaks alates lasteaiast ning ka kutsestandardis on koolieelse lasteasutuse õpetaja läbiva pädevusena sätestatud digipädevus. Paljud lasteaiaõpetajad on aga õppinud ajal, mil digitehnoloogia polnud veel õppekavas. Artikli eesmärk on selgitada ja võrrelda lasteaiaõpetajate ning koolieelse lasteasutuse õpetajaks õppivate üliõpilaste hinnanguid oma aine-, pedagoogika- ja tehnoloogiateadmistele TPACKi raamistikust lähtudes. Andmeid koguti 2014.-2015. aastal Eesti kontekstis valideeritud ankeedi abil 62-lt Tartu Ülikooli koolieelse lasteasutuse õpetaja õppekava üliõpilaselt ja 136-lt Tartu lasteaia õpetajalt. Tulemused näitavad, et kui pedagoogika- ja aineteadmisi hindavad lasteaiaõpetajad kõrgemalt kui üliõpilased, siis tehnoloogia integreerimise teadmistes puudub uuritavate rühmade vahel oluline erinevus. Seega tuleks pöörata enam tähelepanu juba töötavate lasteaiaõpetajate täienduskoolitustele.
\end{abstract}

Võtmesõnad: koolieelse lasteasutuse õpetajad, üliõpilased, võrdlusuuring, tehnoloogia-, pedagoogika- ja aineteadmised, TPACK

\section{Sissejuhatus}

Digitehnoloogia on levinud meie igapäevaellu ja paratamatult täidab see üha suuremat osa väikeste laste elus, hõlbustades nende arengut ja õppimist. Loomulikult peab teadvustama ka võimalikke probleeme, mis võivad tehnoloogia ${ }^{2}$ kasutusega kaasneda, kuid siiski usutakse tänapäeval, et tehnoloogiat on

Arvutiteaduse instituut, Tartu Ülikool, J. Liivi 2, 50409 Tartu; piret.luik@ut.ee.

Artiklis kasutatakse termineid tehnoloogia ja digitehnoloogia sünonüümidena. 
vaja integreerida juba koolieelsesse õppesse. Kindlasti on otstarbekam käsitada tehnoloogiat pedagoogilise kasutegurina, mitte aga seda üldse vältida (Liang, Chai, Koh, Yang, \& Tsai, 2013), sest praegusajal ei piisa lasteaia õppetegevusteks paberist ja raamatutest (Koolieelse ..., 2008; Vinter \& Kollom, 2012). Samuti on „Eesti elukestva õppe strateegias 2020“ (2014) rõhutatud vajadust rakendada õppimisel ja õpetamisel tänapäevast tehnoloogiat otstarbekalt ja tulemuslikult kõigil haridusastmetel, sh alushariduses.

Digitehnoloogia kasutamine alushariduses võimaldab erinevalt paberil õppematerjalidest edastada infot heli ja video abil, et demonstreerida maailma lastele autentsemal viisil (Nugin, 2013), tekitada interaktsiooni, pakkuda kasutajale valikuvõimalusi ning õppida läbi mängu ja koostöö (Nacher, GarciaSanjuan, \& Jaen, 2016). Eesti lapsed puutuvad digitehnoloogiliste vahenditega kokku järjest varasemas eas (EU Kids Online, 2014). Samas on oluline, et lapse esimesed kontaktid ja kogemused tehnoloogiaga oleksid eesmärgipärased ja läbimõeldud, sest need võivad mõjutada laste heaolu ning edasist õppimist. Seetõttu peaksid lasteaiaõpetajad valdama asjakohast didaktikat (Vinter, 2013). Ka õpetajate kutsestandardi kuuenda taseme kirjelduses on sätestatud läbiva kompetentsina nõue, et õpetajad peavad kasutama sobivaid digitehnoloogilisi vahendeid ja võimalusi nii õpikeskkonna kujundamisel kui ka õpitegevuste läbiviimisel (Kutsestandard ..., 2017).

Uurimused on näidanud, et lasteaiaõpetajad ei tunne end lastega tehtavates tegevustes tehnoloogiat kasutades mugavalt ja edukalt, kui neile ei pakuta tehnoloogia integreerimise koolitusi (Jeong \& Kim, 2017; Önkol, Zembat, \& Balat, 2011). Oluliseks uurimisalaks on kujunenud õpetajate kindlustunne, mis on seotud teadmistega õpetajatöö eri valdkondadest (aine, pedagoogika, tehnoloogia), kuna see mõjutab õpetajate tegevusi ja valikuid õpikeskkonna kavandamisel (Nikolopoulou \& Gialamas, 2015). Ka Eestis on kurdetud, et koolieelse lasteasutuse õpetaja õppekava sisaldab vähe aineid, kus õpetataks integreerima digitehnoloogiat õppeprotsessi. Muudatusi on selles valdkonnas küll tehtud, kuid mitmed lasteaedades töötavad õpetajad on õppinud õppekavadel, kus neid oskusi ei õpetatud (Vinter \& Kollom, 2012). Samas on järjest suurenenud lasteaiaõpetajate osakaal Hariduse Infotehnoloogia Sihtasutuse (HITSA) korraldatavatel tehnoloogiakoolitustel (HITSA, 2016). Juba lasteaias töötavate õpetajate puhul on tähtis, et neil oleksid peale pedagoogiliste ja lasteaia riiklikus õppekavas (2008) sätestatud ainevaldkondade teadmiste ka head tehnoloogiateadmised. Kogenud õpetajad on sageli noorte kolleegide ja praktikantide juhendajad, mistõttu peaksid neil kõigis valdkondades olema paremad teadmised kui nende juhendatavatel. Seega on oluline saada ülevaade, millised on lasteaiaõpetajate ja koolieelse lasteasutuse õpetajaks õppivate üliõpilaste (edaspidi: KELA üliõpilaste) teadmised eri valdkondades ning millised on 
nende valdkondade teadmiste vahelised erinevused. Teades, mis valdkondades ei ületa lasteaiaõpetajate teadmised üliõpilaste omasid, saab pakkuda õpetajatele asjakohaseid täienduskoolitusi.

\section{TPACKi raamistik}

Õpetajatöös on ajalooliselt rõhuasetus olnud eri teadmiste valdkondadel: enam on nõutud aineteadmisi (Shulman, 1987) või pandud rohkem rõhku pedagoogikale (Ball \& McDiarmid, 1990). Ainet ja pedagoogikat vaadati varem üksteisest lahus seisvana, kuid Shulman (1987) seadis fookusse nende ühisosa, luues ühe paljudest õpetaja teadmiste mudelitest - pedagoogika, aine ning pedagoogika ja aine integratsioon (PCK) -, mida on aja jooksul mitmed autorid edasi arendanud (Luik, Taimalu, \& Suviste, 2018).

Tehnoloogia integreerimiseks õppeprotsessi on loodud mitmeid tehnoloogia integratsiooni mudeleid, mis on muutunud ajapikku tehnoloogilistest pedagoogilisteks. Tehnoloogiliste mudelite puhul on seatud eesmärgiks, et õpetajad omandaksid tehnoloogia kasutamise teadmisi ja oskusi, kuid pedagoogiliste mudelite puhul on eesmärk, et õpetajad seostaksid oma tehnoloogiateadmisi pedagoogikateadmistega (Özdemir, 2016). Ühe tehnoloogia integratsiooni raamistiku on välja arendanud Mishra ja Koehler (2006), kes lisasid Shulmani (1987) PCK mudelisse kolmanda põhikomponendi - tehnoloogia -, pannes sellega aluse TPACKi raamistikule (algse nimetusega TPCK). Selles raamistikus on ühendatud aine-, pedagoogika- ja tehnoloogiateadmised ning nende ühisosad, et integreerida tehnoloogia ainesse ja pedagoogikasse eesmärgipäraselt. Kuna ka koolieelses eas laste õpetajad vajavad teadmisi, kuidas tehnoloogiat sobival ja efektiivsel moel õpitegevustesse integreerida, siis võib väita, et lasteaiaõpetajate (sh tulevaste õpetajate) seas tehtavad uuringud TPACKi kohta muutuvad üha tähtsamaks (Cheng, 2016; Liang et al., 2013). Tuginedes õpetajate pädevuste mudelite võrdlusele ja õpetajate pädevuste hindamise meetodite analüüsile (Luik et al., 2018) ning lähtudes uurimisprobleemist, ongi siinne uurimus üles ehitatud TPACKi raamistikule.

TPACKi raamistikku kujutatakse sageli Venni diagrammina, mis koosneb kolmest ringist ning neljast ringide ühisosast. Joonisel 1 esitatud kolm ringi kujutavad raamistiku põhivaldkondi: teadmisi tehnoloogiast (technological knowledge, TK), pedagoogikast (pedagogical knowledge, PK) ja aine(te)st (content knowledge, CK). Neli ühisosa kirjeldavad nende kolme põhivaldkonna integratsiooni (Koehler, Mishra, \& Yahya, 2007; Mishra \& Koehler, 2006): 
- tehnoloogia- ja aineteadmised (technological content knowledge, TCK) teadmised, kuidas ainevaldkonna teadmisi tehnoloogia vahendusel efektiivselt õpetada;

- tehnoloogia- ja pedagoogikateadmised (technological pedagogical knowledge, TPK) - teadmised, kuidas tehnoloogia abil toetada õppe- ja hindamismeetodeid;

- pedagoogika- ja aineteadmised (pedagogical content knowledge, PCK) teadmised, mis meetoditega aineteemasid efektiivselt õpetada;

- tehnoloogia-, pedagoogika- ja aineteadmised (technological pedagogical content knowledge, TPACK) - teadmised, kuidas efektiivselt integreerida tehnoloogiat õpikeskkonda ja õppemeetoditesse eri ainekontekstides.

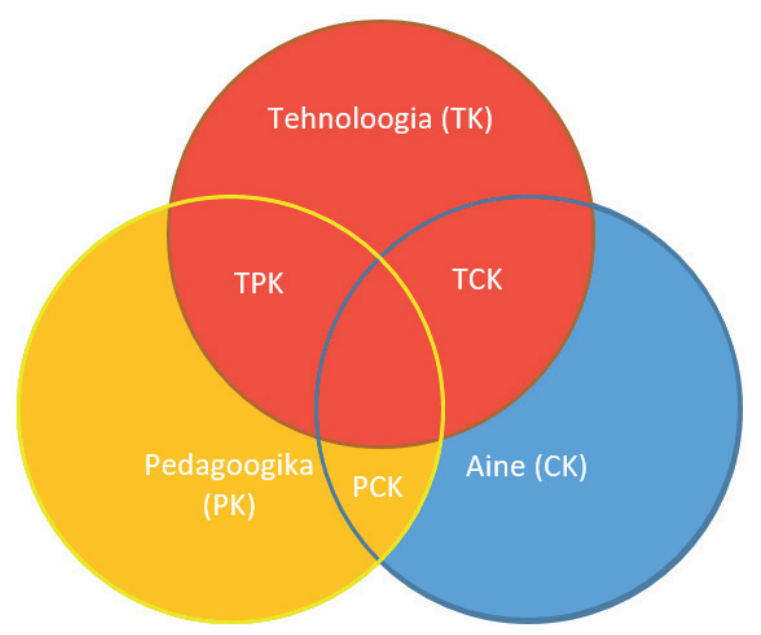

Joonis 1. TPACKi raamistik (Mishra \& Koehler, 2006)

Graham, Borup ja Smith (2012) väidavad, et esialgu ei tähendanud tehnoloogiateadmised selles raamistikus kitsalt teadmisi digitehnoloogia kasutamise kohta, vaid selle all mõeldi kõiki tehnoloogilisi vahendeid, sealhulgas tahvlit, paberit ja pliiatsit. Kuna see aga raskendas TPACKi raamistiku kasutamist uurimiseesmärkidel, tekitades mõõtevahendi valiidsusprobleeme (Graham, 2011), ning kuna enamik uurijaid on kasutanud TPACKi raamistikus sõna tehnoloogia just digitehnoloogia tähenduses (Graham et al., 2012), siis käsitatakse ka siinses uurimuses tehnoloogiana digitehnoloogiat.

TPACKi raamistikku on kasutatud mitmetes uurimustes üle maailma, näiteks Hiinas (nt Dong, Chai, Sang, Koh, \& Tsai, 2015), Singapuris (nt Koh \& Chai, 2014), Ghanas (nt Agyei \& Keengwe, 2012), Türgis (nt Özdemir, 2016), USAs (nt Lee \& Tsai, 2010), Hollandis (nt Rienties et al., 2013), Austraalias 
(nt Bate \& Maor, 2010). See raamistik on võetud aluseks õpetajate täienduskoolituskursuste (nt Koh \& Chai, 2014; Rienties et al., 2013) ja õpetajakoolituse ainete (nt Chai, Koh, Tsai, \& Tan, 2011; Koh \& Chai, 2014) arendamisel. Cheng (2016) väidab, et TPACKi raamistiku tundmine aitab lasteaiaõpetajatel paremini ja efektiivsemalt integreerida digitehnoloogiat nii õppemeetoditesse kui ka ainevaldkondade õpetamisse. Seepärast soovitab ta kasutada TPACKi raamistikku ka õpetajakoolituse õppekava arendamisel (ibid.).

\section{Lasteaiaõpetajate ja õpetajakoolituse üliõpilaste hinnangud oma teadmistele TPACKi valdkondades}

Õpetajate teadmiste hindamine on keeruline protsess, mis vajab valiidseid ja reliaableid mõõtevahendeid (Coe, Aloisi, Higgins, \& Major, 2014; van der Schaaf \& Stokking, 2011). Adekvaatsete tulemuste saamiseks võiks kasutada teste või vaatlusmõõdikuid, kuid eri autorid on leidnud, et nimetatud vahendid ei pruugi sobida. Teadmiste testimine pole kohane viis mõõta õpetajate teadmisi, sest õppeprotsessi keerukuse tõttu võivad eri tingimustes eri vastusevariandid õigeks osutuda (Berliner, 2005). Vaatlused toimuksid küll reaalses kontekstis (Chen, Hendricks, \& Archibald, 2011), kuid vajaksid kvaliteetseid vaatlusprotokolle ja treenitud vaatlejaid (Coe et al., 2014), lisaks on need aja- ja töömahukad (Bakx, Baartman, \& van Schilt-Mol, 2014). Seepärast kasutatakse õpetajate teadmiste ja pädevuste hindamisel palju enesekohaseid ankeete (nt Bakx et al., 2014; Paulick, Großschedl, Harms, \& Möller, 2016; Voss, Kunter, \& Baumert, 2011). Ka TPACKi raamistik on üks neist, mille alusel on loodud õpetajate teadmiste hindamiseks enesekohaseid ankeete. Kuigi ankeetidega saab mõõta vaid hinnanguid, mis ei pruugi vastata tegelikkusele, näitavad uurimused, et ka hinnangud peegeldavad tegelikkust. Näiteks on Cheng (2016) leidnud, et mida kõrgemaid hinnanguid annavad lasteaiaõpetajad oma TPACKi valdkondadele, seda efektiivsemalt suudavad nad vaatlusandmetele tuginedes integreerida tehnoloogiat õppeprotsessi.

Õpetajate ja üliõpilaste hinnangute kohta TPACKi raamistikus on arvukalt uurimusi, kus enamasti on valimiks olnud kooliõpetajad või üliõpilased. Vähem on aga leida alushariduse õpetajate (preschool või early childhood teachers) ja koolieelse lasteasutuse õpetajaks õppivate üliõpilaste kohta tehtud uurimusi (Liang et al., 2013). Seega on oluline uurida koolieelses haridusasutuses õpetavaid (ka tulevasi) õpetajaid laialdasemalt, et saada aimu, kuidas nad hindavad oma teadmisi eri valdkondade kohta. Üks tähtis valdkond on tehnoloogia integreerimine lastega tehtavatesse tegevustesse. 
On leitud, et lasteaiaõpetajad on andnud TPACKi raamistiku teadmistele pigem skaala keskpunktist kõrgemaid hinnanguid (Chuang \& Ho, 2011; Liang et al., 2013), kuid näiteks Hongkongis korraldatud uuringus leiti, et lasteaiaõpetajad hindavad oma TPACKi teadmisi skaala keskpunktist madalamalt (Cheng, 2016). Samas nõustuvad lasteaiaõpetajad sellega, et digitehnoloogia efektiivne ja oskuslik kasutamine on lasteaias hädavajalik ning aitab lapsi motiveerida (ibid.). Seevastu Taiwanis tehtud uuring näitab, et alushariduse õpetajad hindavad seitsmest TPACKi valdkonnast kõige kõrgemalt pedagoogikateadmisi, aineteadmisi ning pedagoogika- ja aineteadmiste integreerimist, kõige madalamad hinnangud annavad aga tehnoloogiateadmistele (Chuang \& Ho, 2011; Liang et al., 2013) ja tehnoloogiat sisaldavatele valdkondadele (TPACK, TPK ja TCK) (Liang et al., 2013).

Eraldi uurimusi selle kohta, milliseid hinnanguid annavad alushariduse õpetajaks õppivad üliõpilased oma teadmistele TPACKi eri valdkondades, ei õnnestunud leida. Ka Keser, Yilmaz ja Yilmaz (2015) väidavad, et enamik uurimusi puudutab just õpetajate TPACKi teadmisi. Võrreldud on klassiõpetajaks ja lasteaiaõpetajaks õppijaid (Özdemir, 2016), mõnes uurimuses on valimis teiste üliõpilaste seas ka tulevased lasteaiaõpetajad (Keser et al., 2015; Yurdakul, Odabasi, Kilicer, Coklar, Birinci, \& Kurt, 2012). Singapuris on uuritud klassiõpetaja eriala üliõpilasi (Chai et al., 2011; Koh \& Tsai, 2014; Koh, Chai, \& Tsai, 2010).

Uurimustes on leitud, et sama moodi nagu lasteaiaõpetajad on ka eri erialade üliõpilaste, sh lasteaiaõpetajaks õppivate üliõpilaste hinnangud kõigile TPACKi teadmiste valdkondadele skaala keskpunktist kõrgemad (Keser et al., 2015; Koh et al., 2010; Özdemir, 2016), sõltumata õpinguaastast. Ka uuringus seitsme eriala üliõpilastega, kes olid õpetajakoolituse eri etappides, olid lasteaia- ja klassiõpetaja eriala üliõpilaste keskmised TPACKi skoorid teiste omadest oluliselt suuremad (Keser et al., 2015). Erinevalt lasteaiaõpetajate tulemustest on aga üliõpilaste puhul leitud TPACKi valdkondade lõikes vastuolulisemaid tulemusi. Kuna uurimuste valimisse kuuluvad üliõpilased on olnud õpetajakoolituse eri etappides, siis see võib olla ka nende vastuoluliste tulemuste põhjus. Näiteks, Singapuris õpetajakoolituse esimest semestrit alustanud üliõpilased hindasid ühes uuringus kõige kõrgemalt oma pedagoogikateadmisi (Koh et al., 2010), teises uuringus aga tehnoloogia-pedagoogikateadmisi (Chai et al., 2011), kõige madalamalt aga aineteadmisi (Chai et al., 2011; Koh et al., 2010). Seevastu Türgi õpetajakoolituse viimase semestri üliõpilased andsid kõrgeimad hinnangud pedagoogika ja tehnoloogia põhivaldkondadele, madalaimad mõlema kombinatsioonile aineteadmistega (Öz, 2015). Eesti õpetajakoolituse erialade üliõpilastega tehtud uuringust ilmnes, et kõige kõrgemalt hinnatakse tehnoloogia ja selle integreerimisega seotud teadmisi, kõige 
madalamalt aga pedagoogikateadmisi (Luik et al., 2018). Kuna õppekavad erinevad riigiti, siis see võib olla samuti tulemuste erinevuse põhjus.

Õpetajaid ja õpetajakoolituse üliõpilasi võrdlevaid uurimusi on vähe (Dong et al., 2015). Neis üksikuteski on uuritavad olnud teistelt haridusastmetelt, mitte koolieelsete lasteasutuste õpetajad ega KELA üliõpilased. Uurides koolieelse lasteasutuse õpetajaid, on Chuang ja Ho (2011) jõudnud järeldusele, et TPACKi raamistiku profiilid erinevad vanuserühma ja staaži alusel. Nooremad (kes võivad siinse uurimuse kontekstis olla ka näiteks üliõpilased) tajuvad end paremana tehnoloogiateadmistes, kogenumad õpetajad aga pedagoogikateadmistes ning pedagoogika- ja aineteadmiste integreerimises. Järgnevalt tutvustataksegi kolme võrdlusuuringu tulemusi.

Saltan ja Arslan (2017) on võrrelnud Türgi õpetajate ja õpetajakoolituse üliõpilaste (loodusteaduste, matemaatika, IKT, klassiõpetajate) hinnanguid, kuid nende skaala sisaldas vaid TPACKi raamistiku tehnoloogiavaldkondi. Autorid leidsid, et mõlemad rühmad andsid teiste TPACKi tehnoloogiat sisaldavate valdkondadega võrreldes kõrgemad hinnangud tehnoloogia- ja aineteadmiste integreerimisele, seevastu kõige madalamalt hindasid üliõpilased kolme valdkonna integreerimist, õpetajad aga tehnoloogiateadmisi. Üllatavana selgus, et TPACKi hinnangud üliõpilaste ja õpetajate vahel ei erinenud, kuigi oletati, et õpetajatel on suuremad TPACKi skoorid kui üliõpilastel. Põhjenduseks võib olla heal tasemel õpetajakoolitus, kus üliõpilasi valmistatakse õpetajatööks hästi ette (ibid.).

Erinevalt Saltani ja Arslani (2017) uuringust kasutati Hiinas (Dong et al., 2015) ja Singapuris (Koh \& Chai, 2014) tehtud võrdlusuuringus kõiki seitset TPACKi raamistiku valdkonda. Hiina üliõpilased andsid kõrgeima hinnangu tehnoloogia- ja pedagoogikateadmistele (Dong et al., 2015) ja Singapuri üliõpilased tehnoloogiateadmistele (Koh \& Chai, 2014). Õpetajad aga hindasid Hiina uuringus kõrgeimaks pedagoogikateadmisi (Dong et al., 2015) ning Singapuris aineteadmiste ja pedagoogika-aineteadmistega seotud valdkondi (Koh \& Chai, 2014). Madalaima hinnangu andsid üliõpilased aineteadmiste kohta, õpetajad aga kõigi kolme valdkonna integreerimise kohta (Dong et al., 2015). Hiina uuringu tulemused näitasid, et õpetajate hinnangud olid kõigis seitsmes TPACKi valdkonnas oluliselt kõrgemad kui üliõpilastel (Dong et al., 2015). Huvitavaks peeti tulemust, et õpetajad hindasid üliõpilastega võrreldes kõrgemalt oma tehnoloogiateadmisi, sest enamasti oletatakse, ja see oletus leiab sageli ka kinnitust, et nooremate (s.h üliõpilaste) teadmised tehnoloogiavaldkonnas on paremad kui vanematel. Uurijad põhjendasid seda uuringus osalenud õpetajate töökohaga kindlas piirkonnas (Peking), kus tehakse õpetajate IKT teadmiste parendamiseks ülikoolidega tõhusat koostööd (ibid.). 
Võrreldes üliõpilaste ja õpetajate antud hinnanguid, ilmneb, et tulemused on mõneti vastuolulised. Türgi õpetajate ja üliõpilaste hinnangute vahel ei leitud olulisi erinevusi üheski tehnoloogiat sisaldavas valdkonnas (Saltan \& Arslan, 2017), kuid Hiinas andsid õpetajatega võrreldes õpetajakoolituse üliõpilased oluliselt madalamad hinnangud kõigis seitsmes TPACKi raamistiku valdkonnas (Dong et al., 2015).

Kuigi TPACKi raamistikku on laialdaselt kasutatud eri uurimustes, on siiski tehtud vähe üliõpilaste ja õpetajate võrdlusuuringuid (Dong et al., 2015) ja need on kohati vastuolulised. Kuna õpetajakoolitus ja õpetajate täienduskoolitus on riigiti erinev, siis ei saa teistes riikides saadud uurimistulemusi üheselt üle võtta ning vaja on uurida olukorda Eestis. Tuleks välja selgitada, kuivõrd erinevad Eesti lasteaiaõpetajate ja KELA üliõpilaste hinnangud teadmistele, sest lasteaiaõpetajatel peaksid olema üliõpilastest paremad teadmised kõigis valdkondades, kuna peale laste õpetamise juhendavad nad ka üliõpilasi ning on algajatele õpetajatele mentoriks. Seetõttu seati praeguse uurimuse eesmärgiks selgitada ja võrrelda lasteaiaõpetajate ja KELA üliõpilaste hinnanguid oma aine-, pedagoogika- ja tehnoloogiateadmistele TPACKi raamistiku alusel. Artiklis otsitakse vastust järgmistele uurimisküsimustele.

- Missugused on lasteaiaõpetajate ja KELA üliõpilaste hinnangud endi teadmistele raamistiku eri valdkondades?

- Missugused erinevused on lasteaiaõpetajate ja KELA üliõpilaste hinnangute vahel raamistiku eri valdkondades?

\section{Metoodika}

\section{Valim ja andmekogumine}

Uurimuse valimisse kuuluvad KELA üliõpilased valiti Tartu Ülikoolist. Kuna kõik tulevased õpetajad peavad õpetajakoolituse õpingute alguses läbima aine „Õppe kavandamine“ ja hakkavad käima koolipraktikal, siis valiti uuritavateks just selle aine üliõpilased. Aine avaseminarides tutvustati uuringut, seejärel jagati üliõpilastele ankeedid, rõhutades, et uuringus osalemine on vabatahtlik ning see ei ole seotud aine läbimisega. Samuti tagati vastajate anonüümsus. Ankeedile vastas 2014. aasta septembris 35 ja 2015. aasta septembris 27 üliõpilast, mis teeb kahe aasta peale kokku 62 KELA üliõpilast. Vastanutest vaid üks oli meessoost. 57 (92\%) üliõpilastest õppis ankeedile vastamise ajal teisel kursusel, kus on nimetatud aine läbimine ette nähtud. Viis vastanut (8\%) olid KELA õppekava kolmanda kursuse üliõpilased. Üliõpilaste keskmine vanus oli 21,3 aastat (standardhälve 2,52), jäädes vahemikku 19-29 aastat. 
Kuna kolmest Tartu Ülikooli innovatsioonikoolide rühma kuuluvast lasteaiast kaks on Tartust, siis valiti kõik uuringus osalevad lasteaiaõpetajad Tartu lasteaedadest. Kõigi Tartu lasteaedade juhtidega võeti jaanuaris 2015 ühendust ja saadeti neile ankeedi link, vajaduse korral ka paberankeedid. Ka lasteaiaõpetajatel oli ankeedile vastamine vabatahtlik ning anonüümne. Kokku vastas ankeedile 220 õpetajat Tartu linna lasteaedadest. Andmetest eemaldati ankeedid, kus vastaja staaž lasteaias oli alla ühe aasta, vastajal polnud bakalaureuse- või magistrikraadi ning vastaja töötas lasteaias kas muusikaõpetaja, logopeedi vms ametikohal. Seega jäi sellesse uuringusse 136 lasteaiaõpetajate ankeeti. Kõik vastanud lasteaiaõpetajad olid naissoost. Noorimad vastajad olid alla 25aastased (6 õpetajat), vanimad üle 61aastased (13 õpetajat). Lasteaiaõpetajate vanuse mediaanvahemik oli 41-45 aastat. Vastanutest 116 (85\%) olid bakalaureusekraadiga ning 20 (15\%) magistrikraadiga. Staaži mediaanvahemik oli 11-15 aastat.

\section{Mõõtevahend}

Andmeid koguti TPACKi raamistikule (Mishra \& Koehler, 2006) tugineva ankeediga, millega mõõdeti üliõpilaste ja õpetajate hinnanguid oma teadmistele. Ankeet koostati Tartu Ülikooli ja Ida-Soome Ülikooli ekspertidest koosnevas töörühmas (lisateavet ankeedi koostamise kohta vt Luik et al., 2018). Lasteaiaõpetajate ja KELA üliõpilaste jaoks ankeeti kohandati, nt asendati sõna klass sõnaga rühm, aine asemel kasutati terminit ainevaldkond. Kõik väited olid viiepunktiskaalal, kus „,5“ tähendas, et vastaja teadmised/oskused selles väites kirjeldatu kohta on maksimaalselt head, ja "1“ tähendas, et vastaja oskused/ teadmised selles väites kirjeldatu kohta puuduvad.

Kinnitava faktoranalüüsi (CFA) abil on varem leitud Eesti kontekstis kolmefaktoriline mudel kirjeldusvõimega 55,24\%, mille sobivus- ehk headusindeksid olid järgmised: $\chi^{2}=2196,271, \chi^{2} / d f=1,87$, TLI $=0,92, \mathrm{CFI}=0,92$, RMSEA $=0,05$, SRMR $=0,07$ (Luik et al., 2018). Standardiseeritud faktorlaadungid jäid vahemikku 0,58-0,84 ja väidete reliaablus vahemikku 0,33-0,71. Eesti kontekstile vastava TPACKi raamistikul põhineva skaala kolm faktorit olid järgmised:

- teadmised tehnoloogiast ja selle integreerimisest (29 väidet) - sellesse faktorisse koondusid TPACKi raamistiku valdkonnad TK (nt „Oskan kasutada erinevaid tarkvarasid, näiteks koostöövahendeid, suhtlusvõrgustikke, testide ja küsitluste koostamise keskkondi, piltide ja videote üleslaadimise keskkondi, graafilise kujundamise tarkvara, video redigeerimise tarkvara"), TPK (nt „Tean, kuidas tehnoloogia võib mõjutada rühmas kasutatavaid õpetamismeetodeid“), TCK (nt „Oskan kasutada erinevaid esitustehnoloogiaid, mis aitavad lastel ainevaldkondadest paremini aru saada") ja TPACK (nt „Tean, kuidas valida sobivaid tehnoloogiaid eri ainevaldkondade õpetamise tõhustamiseks"); 
- pedagoogikateadmised (14 väidet) - PK (nt „Oskan kasutada rühmas erinevaid õpetamismeetodeid“) ja PCK (nt „Tean, kui põhjalikult ja laiaulatuslikult ma oma rühmas mõisteid õpetan“);

- aineteadmised (8 väidet) - CK (nt „Tean, kuidas eri ainevaldkondade teadmisi saab kasutada igapäevaelus").

Selles uuringus oli tehnoloogia ja selle integreerimise faktori korral Gutmanni poolte reliaabluse (split-half reliability) koefitsient 0,93, pedagoogikateadmiste faktori korral 0,94 ja aineteadmiste korral 0,91. TPACKi skaalale lisaks olid ankeedis taustaandmed (sugu, vanus, üliõpilaste puhul kursus, lasteaiaõpetajate puhul staaž).

\section{Andmeanalüïs}

Andmeanalüüsi aluseks võeti eespool kirjeldatud varasem faktormudel (Luik et al., 2018). Esmalt leiti iga vastaja jaoks faktortunnuse väärtus faktorisse kuuluvate väidete vastuste aritmeetilise keskmisena. Et välja selgitada, milline on esimese uurimisküsimuse korral faktorite pingerida lasteaiaõpetajatel ja KELA üliõpilastel, kasutati mitmest võrdlemist (multiple comparison) Bonferroni korrektsiooniga. Sõltumatute valimite $t$-test võimaldas teise uurimisküsimuse korral võrrelda lasteaiaõpetajate ja üliõpilaste hinnanguid skaala eri valdkondades.

\section{Tulemused}

Esmalt analüüsiti KELA üliõpilaste ja lasteaiaõpetajate hinnanguid teadmistele TPACKi raamistiku eri valdkondade kohta ühe alamrühma piires ning võrreldi leitud faktoreid omavahel alamrühma sees. Faktorite kirjeldav statistika ja pingerida mõlema alamrühma kohta on esitatud tabelis 1 .

Tabel 1. KELA üliõpilaste ja lasteaiaõpetajate hinnangute põhjal arvutatud TPACKi faktorite kirjeldav statistika ning pingeread

\begin{tabular}{lcccccccccc}
\hline & \multicolumn{4}{c}{ KELA üliõpilased $(N=62)$} & \multicolumn{4}{c}{ Lasteaiaõpetajad $(N=136)$} \\
\cline { 2 - 12 } Faktor & Min & Max & $M$ & $S D$ & Jrk & Min & Max & $M$ & $S D$ & Jrk \\
\hline TK & 2,3 & 4,6 & 3,47 & 0,48 & 1 & 1,1 & 4,7 & 3,33 & 0,72 & 3 \\
\hline PK & 1,4 & 4,4 & 3,14 & 0,61 & $2-3$ & 2,4 & 5,0 & 4,05 & 0,48 & 1 \\
\hline CK & 1,1 & 4,6 & 3,08 & 0,65 & $2-3$ & 2,5 & 5,0 & 3,98 & 0,55 & 2 \\
\hline
\end{tabular}

Märkus. TK = teadmised tehnoloogiast ja selle integreerimisest; PK = pedagoogikateadmised, $C K=$ aineteadmised; $\min =$ minimaalne hinnang; $\max =$ maksimaalne hinnang; $M=$ keskmine hinnang; $S D=$ standardhälve, jrk - koht pingereas. 
KELA üliõpilaste puhul ilmnesid faktorite vahel statistiliselt olulised erinevused $(F(2,60)=13,833 ; p<0,01$; vt ka tabel 1$)$. Mitmene võrdlus Bonferroni korrektsiooniga näitas, et KELA üliõpilaste hinnangud teadmistele tehnoloogiast ja selle integreerimisest olid oluliselt kõrgemad võrreldes nende hinnangutega pedagoogika- ja aineteadmistele (mõlemal juhul $p<0,01$ ), kuid pedagoogika- ja aineteadmistele antud hinnangute vahel polnud statistiliselt olulist erinevust $(p=0,66)$.

Lasteaiaõpetajate puhul ilmnesid statistiliselt olulised erinevused kõigi kolme faktori vahel $(F(2,134)=84,229 ; p<0,01$; vt ka tabel 1$)$. Mitmesest võrdlusest Bonferroni korrektsiooniga selgus, et lasteaiaõpetajad hindasid kõige kõrgemalt pedagoogikateadmisi (erinevus hinnangutest teadmistele tehnoloogiast ja selle integreerimisest: $p<0,01$; erinevus hinnangutest aineteadmistele: $p<0,05)$ ning kõige madalamalt teadmisi tehnoloogiast ja selle integreerimisest (erinevus võrreldes mõlema teise faktoriga: $p<0,01$ ).

Võrreldes sõltumatute valimite $t$-testiga KELA üliõpilaste ja lasteaiaõpetajate kolme faktori koondhinnanguid, ilmnesid statistiliselt olulised erinevused kahes faktoris (vt tabel 2). Lasteaiaõpetajad hindasid oma pedagoogika- ja aineteadmisi kõrgemalt kui KELA üliõpilased, kuid hinnangutes tehnoloogiateadmistele ning tehnoloogia integreerimisele statistiliselt oluline erinevus puudus.

Tabel 2. KELA üliõpilaste $(N=63)$ ja lasteaiaõpetajate $(N=136)$ hinnangute põhjal arvutatud TPACKi faktorite võrdlus

\begin{tabular}{|c|c|c|c|c|c|c|}
\hline \multirow{2}{*}{ Faktor } & \multicolumn{2}{|c|}{ Üliõpilased } & \multicolumn{2}{|c|}{ Õpetajad } & \multirow{2}{*}{$t$-statistik } & \multirow{2}{*}{$p$-väärtus } \\
\hline & $M$ & SEM & $M$ & SEM & & \\
\hline $\begin{array}{l}\text { Teadmised tehnoloogiast ja } \\
\text { selle integreerimisest }\end{array}$ & 3,47 & 0,083 & 3,33 & 0,056 & 1,681 & 0,095 \\
\hline Pedagoogikateadmised & 3,14 & 0,067 & 4,05 & 0,045 & $-10,333$ & $<0,001$ \\
\hline Aineteadmised & 3,08 & 0,074 & 3,98 & 0,050 & $-10,081$ & $<0,001$ \\
\hline
\end{tabular}

Märkus. $M=$ keskmine hinnang; SEM = aritmeetilise keskmise standardviga.

\section{Arutelu}

Artikli eesmärk on selgitada ja võrrelda lasteaiaõpetajate ning koolieelse lasteasutuse õpetajaks õppivate üliõpilaste hinnanguid oma aine-, pedagoogika- ja tehnoloogiateadmistele TPACKi raamistikust lähtudes. Esmalt otsiti vastust küsimusele, missugused on lasteaiaõpetajate ja KELA üliõpilaste hinnangud endi teadmistele raamistiku eri valdkondades. Nii nagu varasemad uurimused 
(Chuang \& Ho, 2011; Liang et al., 2013), näitasid ka siinse uurimuse tulemused, et Eesti lasteaiaõpetajad hindavad oma teadmisi skaala keskpunktist kõrgemalt. Uurimistulemustest ilmnes ka, et lasteaiaõpetajate hinnangul on nende teadmised kõige paremad pedagoogika valdkonnas ning kõige halvemad tehnoloogia ja selle integreerimise valdkonnas. Varasemates uurimustes on samuti leitud, et õpetajad hindavad kõrgeimaks pedagoogikateadmisi (Chuang \& Ho, 2011; Dong et al., 2015; Liang et al., 2013) ning madalaimaks tehnoloogia integreerimisega seotud teadmisi (Dong et al., 2015; Liang et al., 2013). Erinevalt Singapuri õpetajatest, kes hindasid kõrgeimaks aineteadmiste valdkondi CK ja CPK (Koh \& Chai, 2014), jäid Eesti õpetajate hinnangud aineteadmistele teiseks. Kuna Eestis on lasteaiaõpetajate õpetajakoolituses hakatud alles viimasel ajal tähelepanu pöörama tehnoloogiateadmistele (Vinter \& Kollom, 2012) ning ka alles viimastel aastatel on tehnoloogiaalastel täienduskoolituskursustel osalejate seas suurenenud lasteaiaõpetajate osakaal (HITSA, 2016), siis see võib olla põhjus, miks hinnati tehnoloogia integreerimisega seotud teadmisi kõige madalamalt. Ka teiste riikide kogemused (Liang et al., 2013; Nikolopoulou \& Gialamas, 2015) on näidanud, et staažikamate õpetajate jaoks on täienduskoolituste pakkumine võtmetegur, sest peale teadmiste saavad nad neilt kursustelt ka kindlustunnet tehnoloogia kasutamiseks. Eestiski tasuks ehk juhinduda Chengi (2016) soovitusest, et TPACKi raamistiku tutvustamine võiks olla üks osa õpetajate täienduskoolitusest ning tehnoloogiaalased täienduskoolitused võiksid tugineda sellele raamistikule.

Erinevalt õpetajatest hindasid KELA üliõpilased kõige kõrgemalt tehnoloogia ja selle integreerimise teadmisi, seevastu aine- ja pedagoogikateadmistele antud hinnangud omavahel ei erinenud. Neid tulemusi võib seletada sellega, et Eesti üldhariduskoolides on tehnoloogia integreerimine heal tasemel (OECD, 2015), mistõttu võib see tekitada lõpetajates arusaama, et neil on selles valdkonnas head teadmised. Ka mõnes varasemas uurimuses on üliõpilased hinnanud kõige kõrgemalt valdkondi, mis sisaldavad tehnoloogiat (Chai et al., 2011; Dong et al., 2015; Koh \& Chai, 2014; Luik et al., 2018). Asjaolu, et pedagoogikateadmised osutusid madalamalt hinnatuks, on vastuolus Koh'i jt (2010) uurimistulemustega, mille kohaselt hindavad Singapuri õpetajakoolituse alguses olevad üliõpilased kõige kõrgemalt just pedagoogikateadmisi. Arvestades, et enamik meie uuringus osalenud KELA üliõpilastest oli läbinud aasta õpetajakoolituses, olles teise õppeaasta alguses, siis on ka see tulemus ootuspärane ning vastab Eestis tehtud varasema uuringu tulemustele, mille kohaselt hinnati pedagoogikateadmisi kõige madalamaks (Luik et al., 2018). Seda, et üliõpilased hindavad aineteadmisi madalamaks, on leitud ka mitmes varasemas uuringus (Chai et al., 2011; Dong et al., 2015; Koh et al., 2010; Öz, 2015). 
Teine uurimisküsimus oli, missugused erinevused on lasteaiaõpetajate ja KELA üliõpilaste hinnangute vahel raamistiku eri valdkondades. Tulemustest ilmneb, et lasteaiaõpetajate hinnangud oma pedagoogika- ja aineteadmistele on oluliselt kõrgemad võrreldes üliõpilaste hinnangutega. Ka Chuang ja Ho (2011) on leidnud, et kogenumad õpetajad hindavad algajatest õpetajatest kõrgemalt pedagoogika- ning pedagoogika- ja aineteadmisi. Lisaks on Dong ja tema kolleegid (2015) tuvastanud, et ka Hiina õpetajate hinnangud olid neis valdkondades õpetajakoolituse üliõpilaste omadest kõrgemad. Praeguste uurimistulemuste põhjal selgus aga üllatavalt, et tehnoloogia ja selle integreerimise teadmistes polnud lasteaiaõpetajate ja üliõpilaste hinnangute vahel olulist erinevust. Põhjenduseks võib tuua, et varasemad uurimused tehnoloogiateadmisi sisaldavate valdkondade võrdluse kohta ongi olnud vastuolulised. Kui Saltan ja Arslan (2017) ei leidnud üheski neljast tehnoloogiateadmisi sisaldavast valdkonnast erinevusi õpetajate ja üliõpilaste hinnangute vahel, siis Dongi ja tema kolleegide (2015) uurimistulemuste põhjal on õpetajate hinnangud ka tehnoloogiateadmisi sisaldavates valdkondades kõrgemad kui üliõpilastel. Samuti on Liang ja tema kolleegid (2013) leidnud, et tehnoloogia integreerimise teadmised on positiivses seoses õpetajate kvalifikatsiooniga, kuid Chuang ja Ho (2011) väidavad, et kogenumad oppetajad hindavad tehnoloogia integreerimisega seotud teadmisi madalamalt.

\section{Uurimuse kokkuvõte ja piirangud}

Kokkuvõtvalt võib öelda, et töötavad lasteaiaõpetajad Tartus hindavad kõige kõrgemalt oma pedagoogikateadmisi ja hinnangud nii pedagoogika- kui ka aineteadmistele on neil Tartu Ülikooli KELA üliõpilaste hinnangutest kõrgemad. Samas lasteaiaõpetajate hinnangud oma tehnoloogiateadmistele polnud oluliselt kõrgemad kui KELA üliõpilastel. Seejuures ilmnes, et kui üliõpilased hindasid kolmest TPACKi valdkonnast kõige kõrgemalt tehnoloogiateadmisi, siis lasteaiaõpetajate puhul oli see valdkond just kõige madalamalt hinnatud. Seega, kui lasteaiaõpetajad võiksid olla pädevad juhendama praktikante ning noori kolleege pedagoogika- ja ainevaldkondades, siis ei saa sama öelda tehnoloogia ja selle integreerimise kohta. Töötavad lasteaiaõpetajad vajavad enam täienduskoolitusi, kus õpetatakse, kuidas integreerida tehnoloogiat õppeprotsessi. Seejuures ei piisa vaid neist koolitustest, mis annavad õpetajale tehnoloogiaalaseid teadmisi ja kogemusi, vaid vaja on ka selliseid, mis võimaldaksid integreerida tehnoloogia kasutust pedagoogika- ja ainevaldkonnaga. Samuti võiks tutvustada nii õpetajakoolituses kui ka õpetajate täienduskoolituses TPACKi raamistikku. 
Rohkem rõhku tuleks panna õpetajate endi ning õpetajate ja lasteaedades praktikal olevate õpetajakoolituse üliõpilaste koostööle. Selle käigus avaneks võimalusi noorematel õpetajatel aidata levitada tehnoloogiaalaseid teadmisi ja oskusi vanemate kolleegide seas ning üliõpilastel õpetajate seas. Kogenud õpetajad omakorda saaksid toetada nooremaid pedagoogika- ja ainevaldkonnas, kus nende teadmised on paremad. Samuti võiks seda põhimõtet kasutada õpetajate täienduskoolituses.

Uurimuse esimese piiranguna võib esile tuua, et kasutati enesekohast küsimustikku, millega saadakse siiski vaid hinnangud oma teadmistele, kuid need ei pruugi objektiivselt vastata tegelikele teadmistele. Lisaks moodustati uurimuse valim ühe linna ja ülikooli piires, mis seab ka piirangud tulemuste üldistamisele Eesti kui terviku kohta.

\section{Tänusõnad}

Täname Külli Roodi, kes kogus lasteaiaõpetajate andmed ja oli abiks ankeedi kohandamisel lasteaiaõpetajatele.

\section{Kasutatud allikad}

Agyei, D. D., \& Keengwe, J. (2012). Using technology pedagogical content knowledge development to enhance learning outcomes. Education and Information Technologies, 19(1), 155-171. https://doi.org/10.1007/s10639-012-9204-1

Bakx, A., Baartman, L., \& van Schilt-Mol, T. (2014). Development and evaluation of a summative assessment program for senior teacher competence. Studies in Educational Evaluation, 40, 50-62. https://doi.org/10.1016/j.stueduc.2013.11.004

Ball, D. L., \& McDiarmid, G. W. (1990). The subject-matter preparation of teachers. In W. R. Houston (Ed.), Handbook of research on teacher education: A project of the Association of Teacher Educators (pp. 437-449). New York, London: Macmillan.

Bate, F. G., \& Maor, D. (2010). TPACK and the real world: How useful is the framework? European Association for Practitioner Research on Improving Learning Conference 2010. Retrieved from https://core.ac.uk/download/pdf/61302499.pdf.

Berliner, D. C. (2005). The near impossibility of testing for teacher quality. Journal of Teacher Education, 56(3), 205-213. https://doi.org/10.1177/0022487105275904

Chai, C. S., Koh, J. H. L., Tsai, C.-C., \& Tan, L. L. W. (2011). Modeling primary school pre-service teachers' Technological Pedagogical Content Knowledge (TPACK) for meaningful learning with information and communication technology (ICT). Computers \& Education, 57(1), 1184-1193.

https://doi.org/10.1016/j.compedu.2011.01.007

Chen, W., Hendricks, K., \& Archibald, K. (2011). Assessing preservice teachers' quality teaching practices. Educational Research and Evaluation, 17(1), 13-32.

https://doi.org/10.1080/13803611.2011.578008 
Cheng, E. Y. L. (2016). The integration of ICT in Hong Kong preschool settings: Case studies of two Hong Kong kindergartens (Doctoral dissertation). Nottingham Trent University. Retrieved from http://irep.ntu.ac.uk/id/eprint/30385/1/Yuen\%20 Ling\%20Cheng_2016\%20thesis\%20submission.pdf.

Chuang, H.-H., \& Ho, C.-J. (2011). An investigation of early childhood teachers' Technological Pedagogical Content Knowledge (TPACK) in Taiwan. Journal of Kirsehir Education Faculty, 12(2), 99-117.

Coe, R., Aloisi, C., Higgins, S., \& Major, L. E. (2014). What makes great teaching? Review of the underpinning research. Project Report. London: Sutton Trust.

Dong, Y., Chai, C. S., Sang, G.-Y., Koh, J. H. L., \& Tsai, C.-C. (2015). Exploring the profiles and interplays of pre-service and in-service Teachers' Technological Pedagogical Content Knowledge (TPACK) in China. Educational Technology \& Society, 18(1), 158-169.

Eesti elukestva õppe strateegia 2020 (2014). Tallinn: Haridus- ja Teadusministeerium. Külastatud aadressil https://www.hm.ee/sites/default/files/strateegia2020.pdf.

EU Kids Online (2014). EU Kids Online: Findings, methods, recommendations. London: EU Kids Online, LSE. Retrieved from http://eprints.lse.ac.uk/60512/.

Graham, C. R. (2011). Theoretical considerations for understanding technological pedagogical content knowledge (TPACK). Computers \& Education, 57(3), 19531960. https://doi.org/10.1016/j.compedu.2011.04.010

Graham, C. R., Borup, J., \& Smith, N. B. (2012). Using TPACK as a framework to understand teacher candidates' technology integration decisions. Journal of Computer Assisted Learning, 28(6), 530-546.

https://doi.org/10.1111/j.1365-2729.2011.00472.x

HITSA (2016). 2016. a. konsolideeritud majandusaasta aruanne. Külastatud aadressil http://media.voog.com/0000/0034/3577/files/HITSA_kons_aastaaruanne_2016_ RIKvaade.pdf.

Jeong, H., \& Kim, Y. (2017). The acceptance of computer technology by teachers in early childhood education. Interactive Learning Environments, 25(4), 496-512. https://doi.org/10.1080/10494820.2016.1143376

Keser, H., Yilmaz, F. G. K., \& Yilmaz, R. (2015). TPACK competencies and technology integration self-efficacy perceptions of pre-service teachers. Elementary Education Online, 14(4), 1193-1207. https://doi.org/10.17051/io.2015.65067

Koehler, M. J., Mishra, P., \& Yahya, K. (2007). Tracing the development of teacher knowledge in a design seminar: Integrating content, pedagogy and technology. Computers \& Education, 49(3), 740-762.

https://doi.org/10.1016/j.compedu.2005.11.012

Koh, J. H. L., \& Chai, C. S. (2014). Teacher cluster and their perceptions of technological pedagogical content knowledge (TPACK) development through ICT lesson design. Computers \& Education, 70, 222-232. https://doi.org/10.1016/j.compedu.2013.08.017

Koh, J. H. L., Chai, C. S., \& Tsai, C. C. (2010). Examining the technological pedagogical content knowledge of Singapore pre-service teachers with a large-scale survey. Journal of Computer Assisted Learning, 26(6), 563-573. https://doi.org/10.1111/j.1365-2729.2010.00372.x

Koolieelse lasteasutuse riiklik õppekava (2008). Riigi Teataja I, 2008, 23, 152. Külastatud aadressil https://www.riigiteataja.ee/akt/12970917. 
Kutsestandard. Õpetaja, tase 6 (2017). Hariduse kutsenõukogu. Külastatud aadressil http://www.kutsekoda.ee/et/kutseregister/kutsestandardid/10640560/pdf/opetajatase-6.2.et.pdf.

Lee, M. H., \& Tsai, C. C. (2010). Exploring teachers' perceived self efficacy and technological pedagogical content knowledge with respect to educational use of the World Wide Web. Instructional Science, 38(1), 1-21. https://doi.org/10.1007/s11251-008-9075-4

Liang, J.-C., Chai, C. S., Koh, J. H. L., Yang, C.-J., \& Tsai, C.-C. (2013). Surveying inservice preschool teachers' technological pedagogical content knowledge. Australasian Journal of Educational Technology, 29(4), 581-594. https://doi.org/10.14742/ajet.299

Luik, P., Taimalu, M., \& Suviste, R. (2018). Perceptions of technological pedagogical content knowledge (TPACK) among pre-service teachers in Estonia. Education and Information Technologies, 23(2), 741-755. https://doi.org/10.1007/s10639-017-9633-y

Mishra, P., \& Koehler, M. J. (2006). Technological Pedagogical Content Knowledge: A framework for teacher knowledge. Teachers College Record, 108(6), 1017-1054. https://doi.org/10.1111/j.1467-9620.2006.00684.x

Nacher, V., Garcia-Sanjuan, F., \& Jaen, J. (2016). Interactive technologies for preschool game-based instruction: Experiences and future challenges. Entertainment Computing, 17, 19-29. https://doi.org/10.1016/j.entcom.2016.07.001

Nikolopoulou, K., \& Gialamas, V. (2015). ICT and play in preschool: Early childhood teachers' beliefs and confidence. International Journal of Early Years Education, 23(4), 409-425. https://doi.org/10.1080/09669760.2015.1078727

Nugin, K. (2013). Üldõpetuse rakendamine lasteaias. Tartu: Atlex.

OECD (2015). Students, computers and learning: Making the connection. Paris: OECD Publishing. https://doi.org/10.1787/9789264239555-en

Paulick, I., Großschedl, J., Harms, U., \& Möller, J. (2016). Preservice teachers' professional knowledge and its relation to academic self-concept. Journal of Teacher Education, 67(3), 173-182. https://doi.org/10.1177/0022487116639263

Rienties, B., Brouwer, N., Bohle Carbonell, K., Townsend, D., Rozendal, A.-P., van der Loo, J., ... \& Lygo-Baker, S. (2013). Online training of TPACK skills of higher education scholars: A cross-institutional impact study. European Journal of Teacher Education, 36(4), 480-495. https://doi.org/10.1080/02619768.2013.801073

Saltan, F., \& Arslan, K. (2017). A comparison of in-service and pre-service teachers' technological pedagogical content knowledge self-confidence. Cogent Education, 4(1). https://doi.org/10.1080/2331186X.2017.1311501

Shulman, L. S. (1987). Knowledge and teaching: Foundations of the new reform. Harvard Educational Review, 57(1), 1-23.

https://doi.org/10.17763/haer.57.1.j463w79r56455411

Van der Schaaf, M. F., \& Stokking, K. M. (2011). Construct validation of content standards for teaching. Scandinavian Journal of Educational Research, 55(3), 273289. https://doi.org/10.1080/00313831.2011.576878

Vinter, K. (2013). Digitaalse ekraanimeedia tarbimine 5-7-aastaste laste seas ja selle sotsiaalne vahendamine Eestis. Pedagoogiline vaatekoht (doktoritöö). Tallinn: Tallinna Ülikool. 
Vinter, K., \& Kollom, K. (2012, 1. juuni). Lasteaiaõpetaja koolitus olgu tänapäevane. Oppetajate Leht, 13.

Voss, T., Kunter, M., \& Baumert, J. (2011). Assessing teacher candidates' general pedagogical/psychological knowledge: Test construction and validation. Journal of Educational Psychology, 103(4), 952-969. https://doi.org/10.1037/a0025125

Önkol, F. L., Zembat, R., \& Balat, G. U. (2011). Computer use attitudes, knowledge and skills, habits and methods of preschool teachers. Procedia Computer Science, 3, 343-351. https://doi.org/10.1016/j.procs.2010.12.058

Öz, H. (2015). Assessing pre-service English as a foreign language teachers' technological pedagogical content knowledge. International Education Studies, 8(5), 119-130. https://doi.org/10.5539/ies.v8n5p119

Özdemir, M. (2016). An examination of the Techno-pedagogical Education Competencies (TPACK) of pre-service elementary school and preschool teachers. Journal of Education and Training Studies, 4(10), 70-78. https://doi.org/10.11114/jets.v4i10.1816

Yurdakul, I. K., Odabasi, H. F., Kilicer, K., Coklar, A. N., Birinci, G., \& Kurt, A. A. (2012). The development, validity and reliability of TPACK-deep: A technological pedagogical content knowledge scale. Computers \& Education, 58(3), 964-977. https://doi.org/10.1016/j.compedu.2011.10.012 


\title{
Preschool teachers' and Early Years Teacher curriculum student teachers' assessments of content, pedagogy and technology knowledge and integration of this knowledge
}

\author{
Piret Luik ${ }^{\mathrm{a}}$, Merle Taimalu ${ }^{\mathrm{b}}$ \\ ${ }^{a}$ Institute of Computer Science, University of Tartu \\ ${ }^{b}$ Institute of Education, University of Tartu
}

\section{Summary}

\section{Introduction}

Digital technology is commonly used in our daily lives and plays an increasingly important role in the lives of young children, facilitating the development and learning of children. It is important that the child's first experience with technology would be purposeful because it can affect children's well-being and the future of learning. Therefore, preschool teachers need to be prepared in didactics of digital technology (Vinter, 2013). The professional standards for teachers, level 6, (EstQF level 6) stipulate that one of the recurrent competencies required of teachers is the capability to select and use suitable digital technology that develops the learning environment and supports learning activities (Kutsestandard ..., 2017). It is important for preschool teachers to have a good knowledge of technology in addition to pedagogical and profound knowledge about the subjects included in the National Curriculum for Pre-school Child Care Institutions (2008). Experienced teachers are often mentors for beginner and student teachers, so it is important for them to have a higher level of knowledge in all areas than their mentees.

However, many kindergarten teachers have studied at universities during the years when technology was not included in their curriculum. Therefore, it is important to get an overview of the knowledge of preschool teachers and student teachers of the Early Years Teacher Curriculum (hereinafter: EYT students) in different fields and to find out what are the differences between these areas of knowledge. Knowing the areas in which preschool teachers' knowledge does not exceed that of their students allows offering them the appropriate inservice training.

Institute of Computer Science, University of Tartu, J. Liivi 2, 50409 Tartu, Estonia; piret.luik@ut.ee. 
Because in Estonia digital competences of teachers and students are highlighted (Eesti ..., 2014) and TPACK is widely accepted and applied to investigating teachers' knowledge in several studies (e.g. Bate \& Maor, 2010; Dong et al., 2015; Rienties et al., 2013; Özdemir, 2016), we use TPACK framework. The framework was developed by Mishra and Koehler (2006), who elaborated Shulman's (1987) model adding technology to content and pedagogy, claiming that in teachers' education the primary focus should be on studying how the technology is used for teaching content in a pedagogical way. They named the model TPACK, which consists of seven parts. Three parts of this framework describe basic areas of teacher's knowledge (Content, Technology, and Pedagogical knowledge) and four overlapping parts indicate integrations between these three areas (e.g. Mishra \& Koehler, 2006):

- Technological Content Knowledge (TCK) - knowledge of subject matter integrated with Technology;

- Technological Pedagogical Knowledge (TPK) - knowledge of using technology supporting teaching methods;

- Pedagogical Content Knowledge (PCK) - knowledge of teaching methods in different subject contexts;

- Technological Pedagogical Content Knowledge (TPACK) - knowledge of using technology to implement teaching methods in different subject contexts.

There are a lot of studies about teachers' and students' evaluations according to TPACK framework, but mostly school teachers have been used in these studies as a sample. However, fewer studies are available about preschool teachers (Liang et al., 2013) and the authors did not find any studies about preschool student teachers. Teachers' and students' comparative research has, so far, been limited (Dong et al., 2015). Comparing the evaluations of students with teachers' evaluations, the results are somewhat contradictory. There were no statistically significant differences between teachers' and student teachers' evaluations in a Turkish study (Saltan \& Arslan, 2017), but Chinese students gave a significantly lower rating compared to teachers' in all TPACK framework areas (Dong et al., 2015).

\section{Aim and method}

This study was designed to describe preschool teachers' and EYT students' evaluations on their content, pedagogical and technological knowledge according to the TPACK framework and compare the evaluations of the two groups. Two research questions were posed: What are preschool teachers' and EYT students' evaluations on their knowledge areas? What are the differences between 
preschool teachers' and EYT students' estimates of their knowledge in different areas?

The sample was created by student teachers of the University of Tartu who studied on Early Years Teacher curriculum (62 student teachers) and preschool teachers from Tartu kindergartens who had at least one year of experience (136 teachers). Students' average age was 21.3 years (SD 2.52), median range of the age of teachers was 41-45 years. Median range of teaching experience of preschool teachers was 11-15 years.

The data was collected by questionnaire. For more information about the development and validation of the questionnaire read Luik et al. (2018). According to the results of CFA (ibid.), the TPACK scale corresponding to the Estonian context was divided into three factors: knowledge of technology and its integration - 29 items; pedagogical knowledge - 14 items; content knowledge -8 items. The questionnaire ended with background information. First, for each respondent, the factors' values were calculated as the means of the items in the abovementioned factors. Multiple Comparisons with Bonferroni correction and independent samples $t$-test were used.

\section{Results and discussion}

Preschool teachers perceived knowledge about technology and its integration the weakest and pedagogical knowledge the strongest. Previous studies have also revealed that teachers evaluated pedagogical knowledge as the highest (Chuang \& Ho, 2011; Dong et al., 2015; Liang et al., 2013), and technology integration knowledge as the lowest (Dong et al., 2015; Liang et al., 2013). Teacher training of preschool teachers in Estonia has begun to focus on technology knowledge only in recent years (Vinter \& Kollom, 2012) and preschool teachers' participation in technology training courses has increased (HITSA, 2016). This may explain why the knowledge of technology integration was assessed at the lowest level. Experiences in other countries (Liang et al., 2013; Nikolopoulou \& Gialamas, 2015) have shown that for teachers with longer teaching experience, but without previous knowledge and experience in integrating technology, the provision of in-service education is a critical factor, because, in addition to knowledge, it also provides a sense of confidence in the use of technology. Therefore, as in Cheng (2016), the recommendation that the introduction of the TPACK framework could be part of in-service teacher training, could also be considered in Estonia, and further in-service training in technology use areas could be based on this framework. 
EYT students evaluated knowledge about technology and its integration the highest, but no statistically significant difference was found between the evaluations of pedagogical and content knowledge. In Estonian schools for general education, the integration of technology is at a good level (OECD, 2015), which can create the perception to graduates that they have a good knowledge in this field. Also, in some previous studies students have evaluated technologyincluding areas the highest (Dong et al., 2015; Luik et al., 2018). The result that pedagogical knowledge was not highly evaluated by EYT students is in contradiction with the results of a study conducted in Singapore (Koh et al., 2010), where pedagogical knowledge was evaluated the highest by student teachers. One explanation might be that a majority of students in our study were at the beginning of the second academic year and this result corresponds to a previous study in Estonia (Luik et al., 2018), in which pedagogical knowledge was assessed to be the lowest. Similarly, our results, that content knowledge was assessed lower by EYT students, have also been confirmed in several previous studies (Dong et al., 2015; Koh et al., 2010; Öz, 2015).

As to the second research question, we found that the evaluations of preschool teachers in their pedagogical and content knowledge were significantly higher than EYT students' evaluations. Chuang and Ho (2011) have also found that experienced teachers value pedagogical knowledge and pedagogical content knowledge more than beginner teachers. Surprisingly, on the basis of our results in the knowledge of technology and the integration, there was no significant difference between evaluations of preschool teachers and EYT students. Previous studies have been controversial. While Saltan and Arslan (2017) did not find any differences between teachers and students in any of the four areas of technological knowledge, Dong and colleagues (2015) found that teachers' evaluations were higher in areas of technological knowledge compared to students' ones. Liang et al. (2013) found that technological knowledge was positively related to the qualifications of teachers, but Chuang and Ho (2011) argue that more experienced teachers evaluate technological knowledge lower.

As far as the limitations go, we could refer to the use of a self-reported questionnaire, which provides estimates not only for one's own knowledge, but for those who may not objectively correspond to actual knowledge. Also, the sample was formed on the basis of one town and the University of Tartu, which sets limits on the generalization of the results for all of Estonia.

Keywords: preschool teachers, student teachers, comparative study, technological pedagogical content knowledge (TPACK) 